\title{
Thermal, structural and pasting properties of brazilian ginger (Zingiber officinale Roscoe) starch
}

\section{Roger Santana Kuk, Lucas Henrique Waiga, Cristina Soltovski de Oliveira, Camila Delinski Bet, Luiz Gustavo Lacerda, Egon Schnitzler}

\author{
State University of Ponta Grossa, Ponta Grossa, Brazil
}

Keywords:

Starch

Ginger

Structure

Pasting

Gelatinisation

Article history:

Received 12.11.2017

Received in revised form

18.12.2017

Accepted 29.12.2017

Corresponding author:

Egon Schnitzler

E-mail:

egons@uepg.br

DOI: $10.24263 / 2304-$

974X-2017-6-4-8

\section{Abstract}

Introduction. Unconventional starch sources are interesting industrial alternatives, each presenting different properties. Thermal, morphological, structural and pasting characteristics from ginger starch were investigated in this study.

Materials and methods. Ginger starch was extracted by aqueous process and its characteristics were analysed by thermogravimetry/derivative thermogravimetry, differential scanning calorimetry, rapid viscoamylographic analysis, scanning electron microscopy and X-ray powder diffractometry.

Results and discussion. Similar thermal stability and three mass losses were found for the starch samples. Higher transition temperatures and enthalpy of gelatinisation were found for commercial sample, which was related to the longer amylopectin chains due to B-type crystallinity. Starch obtained from "doce" ginger showed the highest peak and final viscosities associated with the lowest pasting temperature, which is a interesant result for food applications, in addition to the low energy required for gelatinisation. An ellipsoidal shape and no fissures on the surface of the granules were visuallised by microscopy, and the diameter and the commercial sample had the smallest granules. A-type diffraction was obtained for doce and "forte" ginger starches, while commercial starch presented B-type pattern. The highest relative crystallinity was exhibited by the "forte" ginger starch.

Conclusions. Commercial samples presented differences compared to known varieties. Interesting properties were found, highlighting the "doce" ginger variety. 


\section{Introduction}

After cellulose, the main carbohydrate storage material in higher plants is starch. It is synthesized as granules in the amyloplasts and stored in seeds, leaves, roots, etc., from which it can be extracted. This carbohydrate consists of a large number of glucose units linked by glycosidic bonds. These molecules can be linear or branched, called amylose and amylopectin, respectively. The starch granules may have a size between 1-110 $\mu \mathrm{m}$ with rounded, oval, lenticular or polygonal shape according to their biological origin [1-4].

The starch has application in various industrial processes, acting as gelling agents, thickeners, stabilizers, as well as base material for the formation of edible coatings and biodegradable packaging films in the food industry, or as a binder, excipient, diluent, disintegrant and stabilizer, in the pharmaceutical industry [5-7].

In recent years, developments in the food industry have increased and the unique properties of starches as natural polymer have attracted the attention of researchers mainly to obtain new starches with specific characteristics [8-9].

Ginger (Zingiber officinalle) is a rhizome belonging to the Zingiberaceae family. It is originates in South Asia and is a spice with odor and flavour characteristics due to the presence of essential oils. It is widely used in foods and beverages or applied in medicine for gastrointestinal disorders, pain and inflammation [10-11].

The untreated starches present variable characteristics that depend mainly on the origin and the method that were extracted. Therefore, physico-chemical characterisation and instrumental analyses are necessary to understand the behaviour and properties exhibited by these polysaccharides in their native form, allowing for subsequent modifications according to the technological interests. As instrumental analysis, the thermal methods: thermogravimetry (TG) and differential scanning calorimetry (DSC), as well as the fast viscosity analysis (RVA) and scanning electron microscopy (SEM) have been promising. The $\Delta \mathrm{m}$ (mass variation) can be measured when a substance is heated or cooled according to $\Delta \mathrm{T}$ or $\Delta \mathrm{t}$ (temperature or time variation) by thermogravimetry (TG). The differential scanning calorimetry (DSC) measures the heat flow between a sample and a reference material when both are subjected to a controlled temperature change. Through these and some others techniques such as morphological, structural and viscosity analysis changes in starch behaviour can be identified [12-13].

In this investigation we present the extraction of ginger starch, an unconventional source (Zingiber officinalle). The extraction was performed in aqueous medium [14] and the main properties were studied by thermogravimetry/derivative thermogravimetry TG/DTG, differential scanning calorimetry - DSC, rapid viscoamylographic analysis RVA, scanning electron microscopy - SEM and X-ray powder diffractometry - XRD.

\section{Materials and methods}

\section{Materials}

Three samples of Brazilian ginger were collected in Ponta Grossa-PR-Brazil, two of which were known as (a) "doce", (b) "forte", and the third was acquired in local commerce, identified as commercial (c). Each sample was extracted in aqueous medium according to previously described methodology [14]. After the extraction process, each sample was kept in desiccator with calcium chloride until constant mass. 


\section{Methods}

\section{Thermogravimetry/Derivative Thermogravimetry (TG/DTG)}

The mass loss of each sample and the temperatures of each thermal event were obtained using the TGA-50 thermal analysis system (Shimadzu, Japan) with the aid of TA60WS software, for which it was also possible to obtain DTG values, which are a mathematical resource for a more precise identification of the temperatures involved in the mass loss of the samples.

The sample mass was about 7-9 $\mathrm{mg}$ in open alumina crucible. The analysis conditions were: heating from $30{ }^{\circ} \mathrm{C}$ to $650{ }^{\circ} \mathrm{C}$ at a heating rate of $10^{\circ} \mathrm{C} \mathrm{min}{ }^{-1}$, under air flow of 100 $\mathrm{mL} \mathrm{min}^{-1}$. Derivative thermogravimetric (DTG) curves (first derivative of TG curves) were calculated.

Before analysis, the instrument was preliminarily calibrated with standard weight and tested with standard calcium oxalate monohydrate $[9,13]$.

\section{Differential Scanning Calorimetry (DSC)}

The DSC curves were obtained using a DSC-Q200 (TA-Instr., USA) thermal analysis system, with the following parameters: heating rate of $10^{\circ} \mathrm{C} \mathrm{min}{ }^{-1}$ under air flow of $50 \mathrm{~mL}$ $\mathrm{min}^{-1}$, and samples weighing about $2.5 \mathrm{mg}$. A suspension was prepared at a 4:1 ratio (water: starch, w/w) and held for 60 minutes to equilibrate the moisture content. The aluminium crucibles were sealed and after one hour the curves were performed. The instrument was previously calibrated with indium $\left(99.99 \%\right.$ purity, $\left.\mathrm{T}_{\mathrm{p}}=156.6^{\circ} \mathrm{C}, \Delta \mathrm{H}=28.56 \mathrm{~J} \mathrm{~g}^{-1}\right)[5,13]$.

\section{Pasting Properties (RVA)}

For the analysis of pasting properties of each ginger starch sample, the Rapid Visco Analyser instrument (Newport Sci., Australia) was used. A sample containing 8\% starch was suspended in distilled water to a final volume of $28 \mathrm{~g}$ in an aluminum canister. Samples were submitted to a controlled heating process followed by cooling under constant stirring (160 rpm). Initially, the samples were heated from $50{ }^{\circ} \mathrm{C}$ to $90{ }^{\circ} \mathrm{C}$ at a rate of $6{ }^{\circ} \mathrm{C} \mathrm{min}^{-1}$. Then, the sample was maintained at $95{ }^{\circ} \mathrm{C}$ for $5 \mathrm{~min}$, cooled to $50{ }^{\circ} \mathrm{C}$ and maintained at this temperature for $2 \mathrm{~min}$. The whole process lasted 23 minutes [13, 14].

\section{Scanning Electron Microscopy (SEM)}

The morphology and measurements of the starch granules were performed in a Vega 3 (Tescan, Chech Rep.) scanning electron microscope (SEM), under acceleration voltage of $25 \mathrm{kV}$ and $1.500 \mathrm{x}$ magnification. Before analysis the samples were metallised with gold. The area of granules was calculated using Image J 1.47 for Windows software [5].

\section{X-ray Diffractometry (XRD)}

The X-ray Diffraction (XRD) analysis was adapted from the methodology proposed in the literature $[12,15]$, using an Ultima 4 (Rigaku, Japan) X-ray diffractometer. $\mathrm{CuK} \alpha$ radiation $(\lambda=1.5418 \AA)$ and settings of $40 \mathrm{kV}$ and $30 \mathrm{~mA}$ were used. The scattered radiation was detected in the angular range of $5-50^{\circ}(2 \Theta)$, with a scanning speed of $2 \mathrm{~min}^{-1}$ and a step of $0.02^{\circ}$. The degree of relative crystallinity was calculated $[4,12]$ from the ratio 


\section{- Food Technology -}

between peak area and the total diffraction area: $\mathrm{Xc}=\mathrm{Ap} /(\mathrm{Ap}+\mathrm{Ab}) .100$; where: $\mathrm{Xc}=$ relative crystallinity; $A p=$ peak area; $A b=$ basis area.

\section{Statistical Analysis}

The analysis were performed in triplicate. All the averages of the samples were analysed by variance analysis (ANOVA) and Tukey's test with a 95\% confidence interval $(\mathrm{p}<0.05)$, using STATISTICA 7.0 software (StatSoft, Inc., Tulsa, OK, USA).

\section{Results and discussion}

\section{Extraction of Ginger Starch}

The fresh ginger rhizomes (Zingiber officinale Roscoe) were carefully washed and ground in a food processor. The starch extraction was conducted according to the methodology of Bet et al. [3]. Initially an aqueous milling was performed with each ginger sample in industrial blender, followed by sieving (150 and $270 \mathrm{mesh}$ ) and decanting in refrigerator $\left(4-7^{\circ} \mathrm{C}\right)$. The samples were centrifuged at $10000 \mathrm{rpm}$ (Rotina 420R, Hettich Zentrifugen/UK) and the starch was dried in an oven at $40{ }^{\circ} \mathrm{C}$ for $24 \mathrm{~h}$. The samples were kept in a desiccator with anhydrous calcium chloride.

\section{Thermogravimetry/Derivative Thermogravimetry (TG/DTG)}

The TG/DTG curves showed similar behaviour with mass losses distributed in three steps. The first mass loss was due to dehydration followed of a stability period. Starch extracted from yellow ginger tuber showed loss of water up to $100{ }^{\circ} \mathrm{C}$ and a stability plateau up to $277^{\circ} \mathrm{C}$ [15]. According to the literature [16, 17], after the thermal stability and around $300{ }^{\circ} \mathrm{C}$ under oxidising atmosphere, occurs the depolymerisation of the starch. So, the second and third mass losses occurred in consecutive steps, which were attributed to the decomposition and oxidation of organic matter once the TG curves were performed in air atmosphere. Similar results can be observed with other starches [5, 13].

The ash content of each sample was (a) 4.18 , (b) 3.59 and (c) $4.54 \%$, respectively. The obtained results are depicted in Table 1.

TG/DTG curves of starches (a) "doce"; (b) "forte" and (c) commercial

Table 1

\begin{tabular}{|c|c|c|c|c|c|c|}
\hline & \multicolumn{2}{|c|}{$\mathbf{1}^{\text {st }}$ step } & \multicolumn{2}{c|}{$\mathbf{2}^{\text {nd }}$ step } & \multicolumn{2}{c|}{$\mathbf{3}^{\text {rd }}$ step } \\
\hline Sample & $\Delta \mathbf{T} /{ }^{\circ} \mathbf{C}$ & $\boldsymbol{\Delta} \mathbf{m} / \mathbf{\%}$ & $\Delta \mathbf{T} /{ }^{\circ} \mathbf{C}$ & $\mathbf{\Delta} \mathbf{\%} / \mathbf{0}$ & $\Delta \mathbf{T} /{ }^{\circ} \mathbf{C}$ & $\Delta \mathbf{m} / \mathbf{\%}$ \\
\hline $\mathbf{a}$ & $42,8-169,9$ & 12,30 & $276,7-434,4$ & 64,85 & $434,4-593,7$ & 18,67 \\
\hline $\mathbf{b}$ & $31,0-181,3$ & 17,25 & $286,0-430,4$ & 63,10 & $430,4-605,8$ & 16,06 \\
\hline $\mathbf{c}$ & $33,7-185,4$ & 14,24 & $269,4-429,8$ & 64,64 & $429,8-593,8$ & 16,58 \\
\hline
\end{tabular}

$\Delta \mathrm{T}$, temperature range of mass loss; $\Delta \mathrm{m}, \%$ of mass loss

DTG ( $1^{\text {st }}$ derivative of the TG curve) was used to aid in the calculation of the mass loss, as well as in determining the temperature range that each event occurred. 


\section{Differential Scanning Calorimetry (DSC)}

The results of the DSC curves are shown in Figure 1, where the endothermic phenomenon that occurs during heating of the starch in excess of water, called gelatinisation, can be studied.

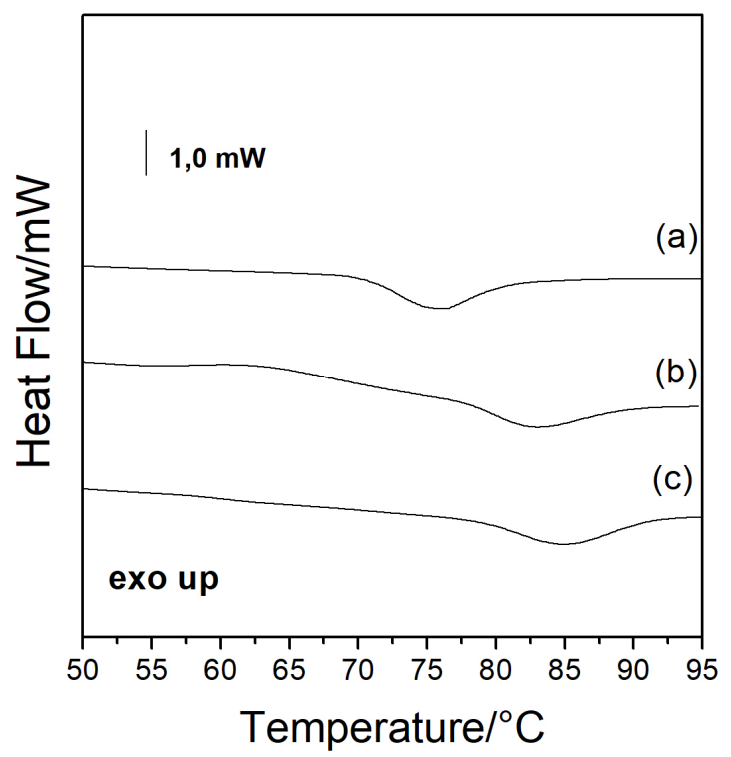

Figure 1. DSC curves of starches (a) "doce"; (b) "forte" and (c) commercial

Starches are practically insoluble in cold water. However, during the heat treatment of starch in the presence of sufficient amount of water, gelatinisation occurs. Amylose is leached into the external solution, when water penetrates the granules, leading to swelling. Thus, destabilisation of the crystalline structure occurs resulting in granular fragmentation and loss of birefringence. Among the factors that may affect this kinetic (the ratio between crystalline and amorphous regions, tend to absorb water more easily), are important in DSC conditions: hermetic crucibles, heating rate, starch:water ratio, as described in Materials and methods.

Each starch analysed showed specific values of onset $\left(T_{0}\right)$, peak $\left(T_{p}\right)$ and conclusion $\left(\mathrm{T}_{\mathrm{c}}\right)$ temperatures as well as the calculated gelatinisation enthalpy $\left(\Delta \mathrm{H}_{\mathrm{gel}}\right)$, which values are in Table 2. Higher values of temperature and $\Delta \mathrm{H}_{\text {gel }}$ were obtained for the commercial sample.

Within the same species, differences in starch properties can be found as a result of the variety of size and shape of the granules, composition, amylose ratio: amylopectin, among other factors [18]. 
DSC Gelatinisation, XRD and SEM results

Table 2

\begin{tabular}{|c|c|c|c|c|c|c|}
\hline & \multicolumn{3}{|c|}{ DSC } & Xesults & XRD & SEM \\
\hline \multirow{2}{*}{ Sample } & $\mathbf{T}_{\mathbf{0}} /{ }^{\circ} \mathbf{C}$ & $\mathbf{T}_{\mathbf{p}} /{ }^{\circ} \mathbf{C}$ & $\mathbf{T}_{\mathbf{c}} /{ }^{\circ} \mathbf{C}$ & $\boldsymbol{\Delta .}_{\mathbf{g e}} / \mathbf{J} \mathbf{g}^{-}$ & $\begin{array}{c}\text { Relative } \\
\text { Cristallinity } / \%\end{array}$ & $\begin{array}{c}\text { Average } \\
\text { diameter/ } \boldsymbol{\mu m}\end{array}$ \\
\hline $\mathbf{a}$ & $70,8 \pm$ & $75,8 \pm$ & $80,0 \pm$ & $9,6 \pm$ & $27,3 \pm 0,72^{\mathrm{a}}$ & $39,7 \pm 6,60^{\mathrm{c}}$ \\
& $0,08^{\mathrm{a}}$ & $0,20^{\mathrm{a}}$ & $0,22^{\mathrm{a}}$ & $0,50^{\mathrm{ab}}$ & & \\
\hline $\mathbf{b}$ & $77,5 \pm$ & $83,2 \pm$ & $88,0 \pm$ & $8,8 \pm$ & $36,2 \pm 1,52^{\mathrm{b}}$ & $24,2 \pm 4,01^{\mathrm{b}}$ \\
& $0,19^{\mathrm{b}}$ & $0,05^{\mathrm{c}}$ & $0,11^{\mathrm{c}}$ & $0,70^{\mathrm{a}}$ & & \\
\hline $\mathbf{c}$ & $78,9 \pm$ & $85,1 \pm$ & $90,1 \pm$ & $10,82 \pm$ & $24,9 \pm 0,87^{\mathrm{a}}$ & $17,7 \pm 2,49^{\mathrm{a}}$ \\
& $0,16^{\mathrm{c}}$ & $0,13^{\mathrm{b}}$ & $0,01^{\mathrm{b}}$ & $0,43^{\mathrm{b}}$ & & \\
\hline
\end{tabular}

(*) To "onset" or initial temperature, Tp peak temperature, Tc "endset" or conclusion temperature, $\Delta$ Hgel gelatinisation enthalpy. Values presented as mean values \pm standard deviation after analysing in triplicate

Values followed by the same letter in the same column do not differ statistically by Tukey's test $(\mathrm{p}<0.05)$

Starch isolated from mango ginger starch (Curcuma amada Roxb.), a rhizome with similar morphology to ginger starch, showed lower transition temperatures, which were attributed to the presence of abundant short amylopectin chains [19]. Regarding gelatinisation enthalpy, turmeric and ginger starches presented higher values than the ginger varieties studied in the present study [20]. Studies attributed higher enthalpy values to the presence of longer chains of amylopectin, requiring higher temperatures for their destructuring [21], according to the crystallinity pattern obtained by X-ray diffraction analysis.

\section{Pasting Properties (RVA)}

The viscosity profiles for the isolated starch of the three ginger varieties are shown in Fig. 2. This analysis results in the pasting properties of a starch, which is of great importance for defining aspects such as cooking and quality of the gel produced [22]. 


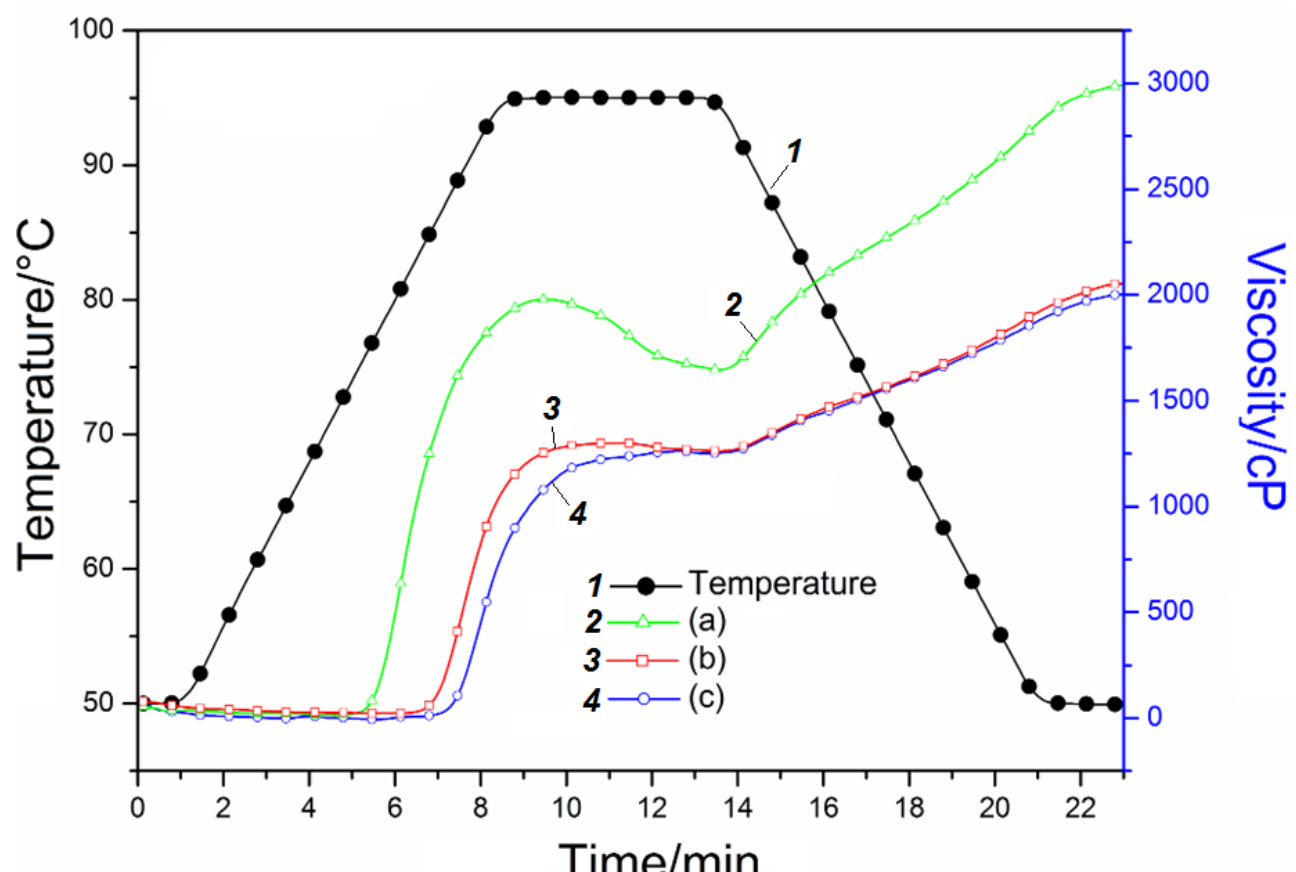

Figure 2. Pasting properties: RVA curves of starches (a) "doce"; (b) "forte" and (c) commercial

During gelatinisation, intragranular forces weaken due to the presence of sufficient water and shear, favouring the absorption of water by the granules, swelling them and resulting in an increase in viscosity. Following this, a critical point of perturbation of the system is reached, with collapse of the structure and reorganisation of the amylose and amylopectin chains. Thus, the viscosity decrease and water expulsion occurs, a process known as breakdown followed by starch retrogradation [23].

Differences can be visualised between the samples, with higher retrogradation and viscosity for sample (a), which belongs to the ginger "doce" variety. Table 3 presents the results extracted from the RVA curves.

RVA Results of starches: (a) "doce"; (b) "forte" and (c) commercial

Table 3

\begin{tabular}{|c|c|c|c|c|c|c|c|}
\hline Sample & $\begin{array}{c}\mathbf{T p} / \\
{ }^{\circ} \mathbf{C}\end{array}$ & $\begin{array}{c}\mathbf{V P} / \\
\mathbf{m P a} \cdot \mathbf{s}\end{array}$ & $\begin{array}{c}\text { Trough/ } \\
\mathbf{m P a} \cdot \mathbf{s}\end{array}$ & $\begin{array}{c}\text { Breakdown/ } \\
\mathbf{m P a} \cdot \mathbf{s}\end{array}$ & $\begin{array}{c}\mathbf{V F} / \\
\mathbf{m P a} \cdot \mathbf{s}\end{array}$ & $\begin{array}{c}\text { Setback/ } \\
\mathbf{m P a} \cdot \mathbf{s}\end{array}$ & $\begin{array}{c}\mathbf{t P} / \\
\mathbf{m i n}\end{array}$ \\
\hline $\mathbf{a}$ & 80.8 & 1979.8 & 1646.2 & 333.7 & 2991.0 & 1345.3 & 9.5 \\
\hline $\mathbf{b}$ & 89.7 & 1295.5 & 1261.9 & 33.6 & 2053.5 & 791.6 & 10.7 \\
\hline $\mathbf{c}$ & 91.9 & 1230.2 & 1254.7 & 24.0 & 2003.8 & 749.1 & 11.1 \\
\hline
\end{tabular}

$\mathrm{Tp}$ - pasting temperature; $\mathrm{VP}$ - peak viscosity; $\mathrm{tP}$ - peak time; $\mathrm{VF}$ - final viscosity. 
Higher pasting temperature was found for commercial variety, which also had lower peak viscosity. Thus, this sample gave lower values of breakdown, tendency to retrogradation and final viscosity. Unlike the "doce" variety, in which there was the formation of a paste more viscous, the lower temperature. These data corroborate with the results obtained by DSC.

High temperatures have also been reported for ginger spent starch $\left(88^{\circ} \mathrm{C}\right)$, which was isolated after the extraction of oleoresin [23]. Braga et al. [20] reported higher peak viscosity (2650 mPa.s), setback (1673 mPa.s) and final viscosity (4060 mPa.s) for starch extracted from Zingiber officinale $\mathrm{R}$.

\section{Scanning Electron Microscopy (SEM)}

The morphologies of the granules were examined by Scanning Electron Microscopy (SEM) and the images are shown in Figure 3. With this technique it was possible to observe that the starch granules have an oval ellipsoidal shape with little round shape. In addition, no cracks were observed on the surface of the granules, as was reported for mango ginger starch [19] and untreated yellow ginger starch [15].

The average diameter was calculated (width and length, in $\mu \mathrm{m}$ ) and values are depicted in Table 2. Starches isolated from Curcuma longa, is also part of the ginger family, and Zingiber officinale $[20,7]$ exhibited diameters close to those found in this study. Marama root starch presented a diameter ranged from 5-38 $\mu \mathrm{m}$ [24].

\section{X-ray Diffractometry (XRD)}

The semicrystalline structure of the granules is formed by the organisation of the growth ring, comprising alternating layers of amorphous and crystalline regions. The double helices of the amylopectin side branches are responsible for the semi-crystallinity of the starch. Thus, three diffraction patterns (A, B and C) can be observed [25]. This was observed in this investigation (Figure 4) and the relative crystallinity of each starch sample was also calculated, results depicted in Table 2.

The samples (a) and (b) showed a strong peak at $17^{\circ}$ at $2 \theta$ and small peaks at 15 and $23^{\circ}$, which classifies them with A-type diffraction pattern, as found for native yellow ginger starch [15].

Unlike these samples, the starch obtained from commercial variety showed a small peak at $5.6^{\circ}$, strong peak at $17^{\circ}$ and a doublet at $22^{\circ}$ and $24^{\circ}(2 \theta)$, as reported for mango ginger starch [19]. According to the literature [26], most tuber and root starches exhibit Btype patterns, which main peaks are centered at $2 \theta$ around $5.5^{\circ}, 15^{\circ}, 17^{\circ}, 19.7^{\circ}, 22.2^{\circ}$ and $24^{\circ}$.

A-type crystallinity encompasses short amylopectin chains and closed branching points, resulting in double helices chains packaged, while B-type has a greater amount of water, present in the central cavity, with longer amylopectin chains, and more open structure [25]. Thus, it is possible to relate these results to those obtained by DSC, where the samples classified with A-type diffraction pattern presented lower values of gelatinisation enthalpy. 


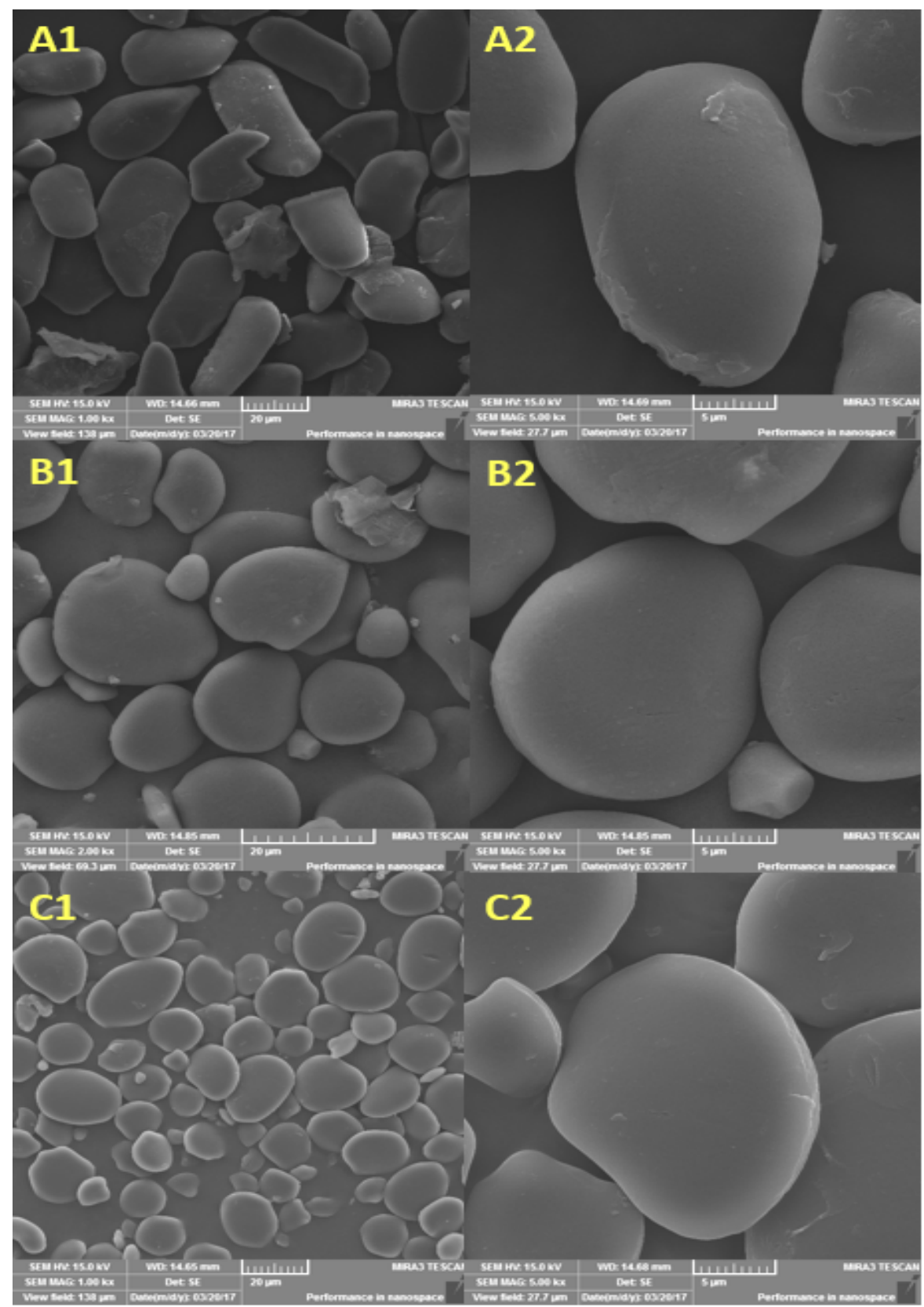

Figure 3. SEM microimages of starches (a) "doce"; (b) "forte" and (c) commercial (magnification $1500 \mathrm{X}$ ). 




Figure 4. XRD of starches (a) "doce"; (b) "forte" and (c) commercial

The degree of relative crystallinity was higher for the "forte" variety sample, followed by "doce" and commercial varieties, respectively. Sukhija, Singh and Riar (2016) [7] found the degree relative crystallinity of $32.61 \% \pm 054$ to native ginger starch although the extraction process was diferent.

\section{Conclusion}

Ginger starch was isolated by aqueous process from different varieties of this rizhom. The commercial sample was compared to the known varieties ("doce" and "forte"), but the results obtained showed that this sample does not belong to these varieties. Similar thermal stability was obtained for the three samples. From DSC, it was visualised that the commercial variety sample required higher temperatures and enthalpy for the gelatinisation of the granules. It can be related to the B-type diffraction pattern, probably due to the longer chains of amylopectin. "Doce" and "forte" varieties showed A-type cristallinity. Lower pasting temperature and higher peak and final viscosities were obtained for starch extracted from "doce" ginger. All samples showed an oval ellipsoidal shape and no surface cracks. 


\section{References}

1. Jamir K., Seshagirirao K. (2017), Isolation, characterization and comparative study of starches from selected Zingiberaceae species, a non-conventional source, Food Hydrocoll., 72, pp. 247-253.

2. Hornung P. S., Ávila S., Lazzarotto M., Lazzarotto S. R. S., Siqueira G. L. A., Schnitzler E., Ribani R. H. (2017), Enhancement of the functional properties of Discoreaceas native starches: mixture as a green modiffication process, Thermochim. Acta., 640, pp. 33-40.

3. Bet C. D., Cordoba L. P., Ribeiro L. S., Schnitzler E. (2016), Common vetch (Vicia sativa) as a new starch source: its thermal, rheological and structural properties after acid hydrolysis, Food Biophys., 11, pp. 275-282.

4. Malucelli L. C., Lacerda L. G.,. Filho M. A. S. C, Fernández D. E. R., Demiate I. M., Oliveira C. S., Schnitzler E. (2015), Porous waxy maize starch. Thermal, structural and viscographic properties of modified granules obtained by enzyme treatment, J. Therm. Anal. Calorim., 120, pp. 525-532.

5. Bet C. D., Waiga L. H., Oliveira C. S., Lacerda L. G., Schnitzler E. (2017 ), Morphological and thermoanalytical study of modified avocado seeds starch with lactic acid., Chem. J. Moldova., 12, (2), pp. 13-18

6. Talele P. B., Sharma K. S., Dalví P. B., Nandan S. S. (2015 ), Isolation of starch from ginger rhizome (Zingiber officinale ), J. Pharmacogn. Phytochem., 3, (6), pp. 157-162.

7. Sukhija S., Singh S., Riar C. S. (2016), Isolation of starches from diferent tubers and study of their physicochemical, thermal, rheological and morphological characteristics, Starch/Stärke., 68, pp. 160-168.

8. Kryazhev V. N., Romanov V. V., Shorokow V. A. (2011 ), Recent advances in chemistry and biotechnology of starch derivatives, Russian J. Bioorg. Chem., 1, pp. $5-12$.

9. Oliveira C. S. Colman T. A. D., Waiga L., Bet C. D., Schnitzler E. (2017) Thermal, morphological and pasting properties of binary mixtures of starches., Braz. J. Therm. Anal., 6, pp. 26-31.

10. Yeh, H., Chuang C., Chen H., Wan C., Chen T., Lin L. (2014 ), Bioactive componentes analysis of two various gingers (Zingiber officinale Roscoe) and antioxidante effect of ginger extracts, LWT-Food Sci. Technol., 55, pp. 329-334.

11. Srinivasan K. (2017), Ginger rhizomes (Zingiber officinale): a spice with multiple health beneficial potentials, Pharma Nutr., 5, pp. 18-28.

12. Lazzarotto S. R. S., Bet C. D., Hornung P. D., Lazzarotto M., Schnitzler E. (2017) Induced effects by oxidation with potassium permanganate on the termal, morphological, colorimetric and pasting properties of corn Starch, Ukrainian Food Journal, 6(1), pp.197-210.

13. Colman T. A. D., Bicudo S. C. W., Lacerda L. G., Filho M. A. S. C., Demiate I. M., Bannach G., Schnitzler E. (2012 ), Characterization of wheat starch by thermoanalytical, rheological and atomic force microscopy techniques, Braz. J. Therm. Anal., 1, pp. 62-65.

14. Cordoba L. P., Bet C. D., Schnitzler E. (2015 ), Study by termal methods of pinhão starch modified with lactic acid. Carpathian J. Food Sci. Technol., 7, pp. $41-47$. 
15. Zhang L., Xie W., Zhao X., Liu Y., Gao W. (2009 ), Study on the morphology, crystalline structure and thermal properties of yellow ginger starch acetates with different degrees of substitution, Thermochim. Acta., 495, pp. 57-62.

16. Aggarwal P., Dollimore P. A. (1998), A thermal analysis investigation of partially hydrolized starch, Thermochim. Acta., 319, pp. 17-25.

17. Lacerda L. G.,Filho M. A. S. C., Demiate I. M., Bannach G., Ionashiro M., Schnitzler E. (2008), Thermal behaviour of corn starch granules under action of fungal $\alpha$-amylase, $J$. Therm. Anal. Calorim., 93, pp. 445-449.

18. Tester, R. F., Karkalas, J., Qi, X. (2004 ), Starch-composition, fine structure and architecture, J. Cereal Sci., 39 (2), pp. 151-165.

19. Policegoudra, R. S., Aradhya, S. M. (2008), Structure and biochemical properties of starch from an unconventional source-Mango ginger (Curcuma amada Roxb.) rhizome, Food Hydrocoll., 22 (4), pp. 513-519.

20. Braga M. E. M., Silvânia R. M. M, Meireles M. A. A. (2006) Effects of supercritical fluid extraction on Cucurma longa $\mathrm{L}$. and Zingiber officinale R. starches, Carbohydr. Polym, 63, pp. 340-346.

21. Aggarwal, V., Singh, N., Kamboj, S. S., Brar, P. S. (2004), Some properties of seeds and starches separated from different Indian pea cultivars, Food Chem, 85(4), pp. 585-590.

22. Qiao-Feng, Z., Ya-Dong, Z., Zhen, Z., Ling, Z., Qing-Yong, Z., Ling, X., Cai-Lin, W. Inheritance Analysis and QTL Mapping of Rice Starch Viscosity (Rapid Visco Analyzer Profile) Characteristics, Rice Sci., 15(3), pp. 186-194.

23. Madeneni, M. M. N., Faiza, S., Ramaswamy, R., Guha, M., Pullabhatla, S. (2011 ), Physico-chemical and functional properties of starch isolated from ginger spent, Starch/Stärke., 63(9), pp. 570-578.

24. Adeboye, A. S., Emmambux, N. M. (2016 ), Physicochemical, morphological, thermal and pasting properties of marama (Tylosema esculentum) storage root starch, Starch/Stärke., 69, pp. 1-9.

25. Fan, X., Zhao, L., Zhang, L., Xu, B., Wei, C. (2017 ), A new allomorph distribution of C-type starch from root tuber of Apios fortunei, Food Hydrocoll., 66, pp. 334-342.

26. Zobel H. F. (1988), Molecules to granules - a comprehensive starch review, Starch/Stärke., 40, pp. 44-50. 